\title{
Simplified Impedance Modeling and Analysis for Inter-Turn Fault of IPM-type BLDC motor
}

\author{
Byeong-Woo Kim*, Kyung-Tae Kim*, and Jin Hur ${ }^{\dagger}$ \\ $\dagger^{*}$ School of Electrical Engineering, University of Ulsan, Ulsan, Korea
}

\begin{abstract}
This paper proposes a finite element method (FEM)-based model of an interior permanent magnet (IPM)-type BLDC motor having stator inter-turn faults. We also propose impedance modeling of the magnetic characteristics. By integrating the developed model with a current-controlled voltage source inverter (CCVSI) model, the distributed characteristics of an inter-turn fault operated by a six-switch inverter are investigated considering speed control. Moreover, this paper presents the flux density distribution and torque characteristics for analyzing the inter-turn fault of an IPM-type BLDC motor. Additionally, fault impedance is required to calculate the circulating current that causes magnetic distortion. Thus, this paper proposes a method for estimating the circulating current taking into account the voltage at the shorted turn and the rotating speed. The analysis data were verified experimentally.
\end{abstract}

Key Words: Circulating current, Fault impedance, Insulation failure, Inter-turn fault

\section{INTRODUCTION}

Owing to their excellent performance characteristics, including high power density and high efficiency, IPM-type motors are actively used in electrical actuation systems that have industrial and transit applications such as HEV and EV, including their motorized systems. In particular, IPM motors operating as BLDC drives have been widely used in many safety-critical application systems because of their robustness and high performance [1], [2].

In such a system, motor reliability is critical. Especially, inter-turn fault in a symmetrical three-phase machine causes a large circulating current to flow and subsequently generates excessive heat in short turns. The heat, which is proportional to the square of the circulating current, can result in complete failure and shutdown of the motor unless the fault is detected early and evasive action is undertaken [3]-[8].

Therefore, many researches have modeled turn faults using lumped parameters of the corresponding magnetic equivalent circuit (MEC). However, magnetic nonlinearity and saturation were not considered in the MEC. Therefore, a model of a motor with inter-turn fault that is reasonably accurate with respect to magnetic nonlinearity is strongly needed. This need arises because the inductance of the motor changes the operating condition due to magnetic saturation and crosscoupled magnetization effects. In addition, the influence of the distorted transient current caused by the turn fault has to include the magnetic distribution and torque characteristics for

\footnotetext{
Manuscript received Aug. 30, 2011; revised Oct. 18, 2011

Recommended for publication by Associate Editor Kyeong-Hwa Kim.

$\dagger$ Corresponding Author: jinhur@ulsan.ac.kr

Tel: +82-52-259-1282, University of Ulsan

* School of Electrical Engineering, University of Ulsan, Korea
}

improving the fault tolerance in high-reliability applications, where continued operation with degraded performance is much more desirable than complete motor shutdown [9]-[13].

Therefore, inter-turn faults have been widely studied to analyze the circulating current. However, because of the complex calculations and the saturation effect, these studies have used only the fault resistance to calculate the current. Fault resistance $\left(R_{f}\right)$, however, must be considered along with the reactance component, because the voltage at the fault turn has an alternating component that is caused by the permanent magnet and the input current.

In this study, we propose a simplified form of fault impedance $\left(Z_{f}\right)$ that considers the variation in the reactance with the rotating speed and the fault fraction $(\mu)$. The proposed fault impedance model can facilitate the calculation of the approximate circulating current, using the parameters of the healthy state and the fault fraction.

We also developed a FEM model in order to perform accurate analysis of inter-turn faults. In addition, the proposed methods can help provide early detection of an inter-turn fault.

\section{INTER-TURN FAULT}

\section{A. Fault impedance modeling}

An inter-turn fault can actually occur within a coil, between two coils of the same phase, and between two different phases. Because the first case is the most common and generally occurs first, only the first case is considered in this paper. It is also assumed that each phase winding consists of turns connected in series and the three-phase windings are wyeconnected with a floating neutral point.

We modeled the turn fault to calculate the circulating current induced in a shorted turn and to analyze the torque 


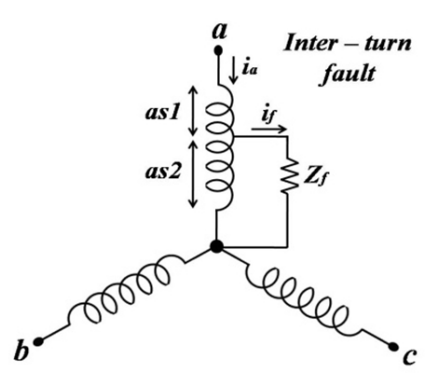

Fig. 1. Schematic of inter-turn fault.

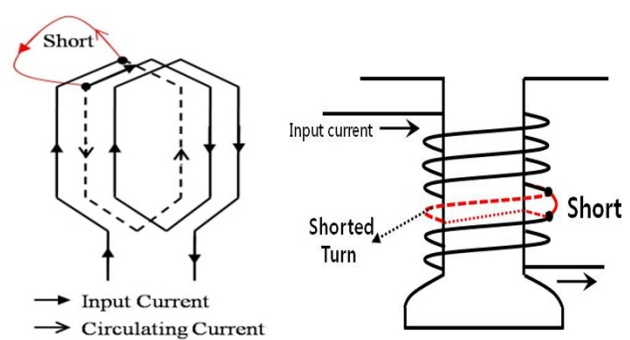

Fig. 2. Winding configuration with the inter-turn fault. characteristics due to the distortion of the input current. The circulating current caused by the turn fault is generated due to the interaction between the faulty shorted turn and the magnetic flux in the rotating air gap. Consequently, the circulating current distorts the input current of the motor. The distorted input current has a direct influence on the torque characteristics and motor vibration and noise.

A schematic of the three-phase windings with an inter-turn fault in the $A$-phase winding is shown in Fig. 1, where asl and as 2 represent the healthy and the shorted turns, respectively, and if represents the circulating current in the shorted turns. Moreover, Fig. 1 implies that regardless of the number of coils in single-phase winding, a series-winding motor with turn fault can be interpreted as a four-winding motor, where the windings are mutually coupled to each other.

Under the above assumptions, the stator line-neutral voltages and the developed torque of IPM motors with an interturn fault on the A-phase winding can be represented by the abc variables in Eq. (1) [3], [14].

In addition, the "Fault fraction" $\mu$, is defined as the ratio of the number of shorted turns to the number of turns per phase, and $Z_{f}$ represents the possible external impedance between the shorted turns. The voltage at the winding of an IPM motor with a turn fault on the $A$-phase winding is represented by Eq. (2), whereas, $\lambda_{a}$ is the linkage flux by the phase coil current, $\lambda_{a r}$ is the linkage flux by the PM, and $L_{a m}=L_{a a}-L_{l s}$. In addition, the voltages at as 1 and as 2 can be obtained using Eqs. (3) and (4), respectively. In Eqs. (3) and (4), $\lambda_{a}{ }^{\prime}=L_{a m}$ $\cdot i_{f}$ is the linkage flux used for consideration of the effect of the turn count as reduced by the shorted turn. When an interturn fault is involved with a small number of $\mu$, the resultant asymmetry of the stator voltage generally has a small effect on the overall stator voltages. Thus, Eq. (4) can be rewritten as Eq. (5). $V_{a n}{ }^{\prime}$ represents the value of the $A$-phase-neutral voltage in the faulty state.

From this equation, the circulating current can be calculated. However, it is quite difficult to obtain accurate values for parameters such as linkage flux, inductance because these parameters have nonlinear characteristics and distribution characteristics with harmonics. Therefore, many researchers use only pure resistance $\left(R_{f}\right)$ in their analyses of the fault state.

$$
v_{s n}^{\prime}=R_{s}^{\prime} \cdot i_{s}^{\prime}+L_{s}^{\prime} \cdot \frac{d i_{s}^{\prime}}{d t}+w\left(\frac{d L_{s}^{\prime}}{d \theta} \cdot i_{s}^{\prime}+\frac{d \lambda_{s r}^{\prime}}{d \theta}\right)
$$

$$
\begin{gathered}
v_{a n}^{\prime}=v_{a s 1}+v_{a s 2}=v_{a}-v_{f}= \\
\left(R_{s} \cdot i_{a}+\frac{d \lambda_{a}}{d t}+w \frac{d \lambda_{a r}\left(\theta_{r}\right)}{d \theta_{r}}\right)-\left(\mu \cdot R_{S} \cdot i_{f}+\mu \cdot w \frac{d \lambda_{a r}\left(\theta_{r}\right)}{d \theta_{r}}\right) \\
v_{a s 1}=(1-\mu)\left[R_{s} i_{a}+L_{a}\left(\theta_{r}\right) \frac{d i_{s}}{d t}+w \frac{d L_{a}\left(\theta_{r}\right)}{d \theta_{r}} i_{s}+w \frac{d \lambda_{a r}\left(\theta_{r}\right)}{d \theta_{r}}\right] \\
-\mu(1-\mu)\left[L_{a m}\left(\theta_{r}\right) \frac{d i_{f}}{d t}+w \frac{d L_{a m}\left(\theta_{r}\right)}{d \theta_{r}} i_{f}\right] \\
v_{a s 2}=R_{f} \cdot i_{f}=\mu\left[R_{s} i_{a}+L_{a}\left(\theta_{r}\right) \frac{d i_{s}}{d t}+w \frac{d L_{a}\left(\theta_{r}\right)}{d \theta_{r}} i_{s}+w \frac{d \lambda_{a r}\left(\theta_{r}\right)}{d \theta_{r}}\right] \\
-\mu\left[R_{s} i_{f}+L_{l s} \frac{d i_{f}}{d t}+\mu\left(L_{a m}\left(\theta_{r}\right) \frac{d i_{f}}{d t}+w \frac{d L_{a m}\left(\theta_{r}\right)}{d \theta_{r}} i_{f}\right)\right] \\
v_{a n}^{\prime}=\frac{R_{f}}{\mu} i_{f}+\left\{R_{s} \cdot i_{f}+\left[L_{l s}+\mu \cdot L_{a m}\right] \frac{d i_{f}}{d t}+\mu \cdot w \cdot \frac{d L_{a m}}{d \theta_{r}} i_{f}\right\}
\end{gathered}
$$

where $v^{\prime}{ }_{s n}=\left[\begin{array}{llll}v_{a s} 1 & v_{a s 2} & v_{b n} & v_{c n}\end{array}\right]^{T} ; R_{s}^{\prime}=\operatorname{diag}\left[(1-\mu) R_{s} \mu R_{s} R_{s}\right.$ $\left.R_{s}\right] ; \lambda^{\prime}{ }_{s r}=\left[\begin{array}{llll}(1-\mu) \lambda_{a r} & \mu \lambda_{a r} & \lambda_{b r} & \lambda_{c r}\end{array}\right]^{T} ; i^{\prime}{ }_{s}=\left[\begin{array}{llll}i_{a} & i_{a}-i_{f} & i_{b} & i_{c}\end{array}\right]^{T}$;

$$
L_{s}^{\prime}=\left[\begin{array}{cccc}
(1-\mu) L_{l s}+(1-\mu)^{2} L_{a m} & \mu(1-\mu) L_{a m} & (1-\mu) M_{a b} & (1-\mu) M_{a c} \\
\mu(1-\mu) L_{a m} & \mu L_{l s}+\mu^{2} L_{a m} & \mu M_{a b} & \mu M_{a c} \\
(1-\mu) M_{b a} & \mu M_{b a} & L_{l s}+L_{b m} & M_{b c} \\
(1-\mu) M_{c a} & \mu M_{c a} & M_{c b} & L_{l s}+L_{c m}
\end{array}\right] .
$$

Thus, this paper proposes the use of simplified fault impedance $\left(Z_{f}\right)$ to consider the variations in reactance for estimation of the circulating current. The reactance depends on the rotating frequency $\left(f_{\text {rot }}\right)$ and on the inductance of the shorted turn $\left(L_{f}\right)$. In addition, the proposed method can be used to estimate the circulating current by using the parameters of the healthy state and the fault fraction. The impedance vector is presented in Fig. 3.

Therefore, one must consider reactance $\left(X_{L}\right)$ to determine the fault resistance in a shorted turn, as shown in the schematic of the faulty phase in Fig. 4. The circulating current can be calculated using Eq. (6), in which $v_{a s 2}$ increases in proportion to the fault fraction. In addition, as shown in Eq. (7), the impedance of the shorted turn is expressed as the vector sum of the fault resistance and fault reactance. Moreover, the fault impedance must be considered to be an inductance variation of the fault fraction.

$$
i_{f[r m s]}=\frac{v_{a s 2[r m s]}}{\left|Z_{f}\right|}
$$




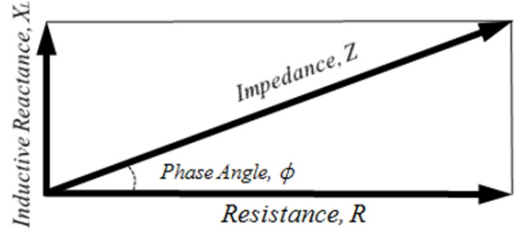

Fig. 3. Impedance vector.

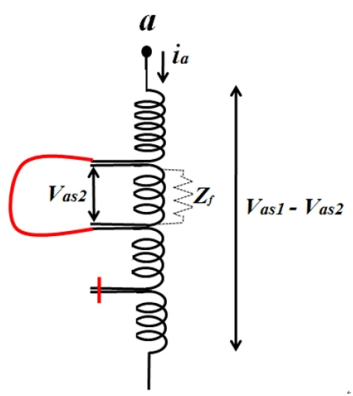

Fig. 4. Impedance modeling.

$$
\left|Z_{f}\right|=\sqrt{R_{f}^{2}+X_{f}^{2}+\left(\frac{d L_{f}}{d \theta} \cdot w\right)^{2}} .
$$

Here $v_{a s 2}=\mu \cdot v_{a}, R_{f}=\mu \cdot R_{s}$, and $X_{f}=2 \cdot \pi \cdot f_{\text {rot }} \cdot \mu \cdot L_{f}$

\section{B. FEM modeling}

The inter-turn fault increased rapidly at the rated speed because the heat generated is proportional to the square of the circulating current. Thus, the circulating current is an important factor in inter-turn faults, which are attributed to the variations in the torque characteristics due to magnetic interruption. In addition, a short-circuit current of this magnitude will cause the breakdown of the adjacent winding insulation. In this work, we developed a 400-W IPM motor with 6 pole/9 slot for the analysis and test, as can be seen in Fig. 5.

Figure 6 shows mesh generation for FEM analysis and winding position of the studied IPM-type motors with interturn fault. The healthy winding (asl) and faulty winding (as2) couple each phase in the electrical circuit. Therefore, the FEMbased model of the IPM-type BLDC motor is developed for estimating the linkage flux and the circulating current. Figure 7 presents the basic scheme of the proposed simulation model with the stator fault for considering the magnetic saturation effect and analyzing the distributed characteristics of the motor. This model includes the shorted turn for calculating the circulating current induced by variations in the magnetic flux that links the shorted turn. Furthermore, the proposed model considers the effect of the B-H curve at the core. The machine parameters are listed in Table I.

\section{RESUlT AND DISCUSSION}

\section{A. Input Current Characteristics}

The simulation result of this paper is analyzed as ratio of shorted winding on the FEM modeling. And it is analyze interturn fault using shorted winding is matched with $L_{a s 2}$ in 6switch inverter circuit in Fig. 7 for more realistic analysis. The simulation results for showing the effect of the fault fraction $\mu$ on the variables of the IPM-type BLDC motor with an interturn fault are shown in Figs. 8-15. Based on the back-emf

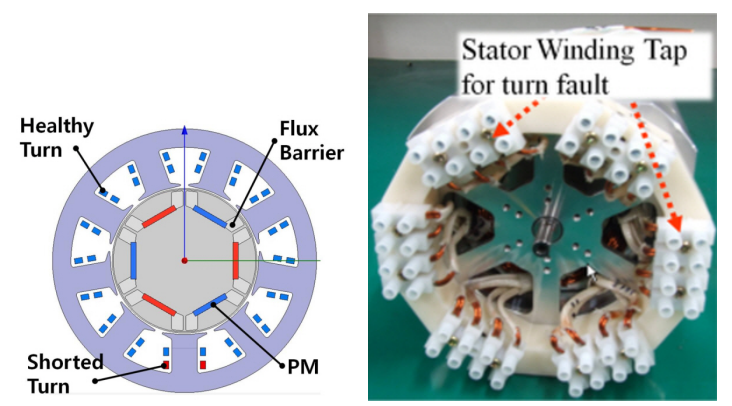

Fig. 5. IPM motor for inter-turn fault test.

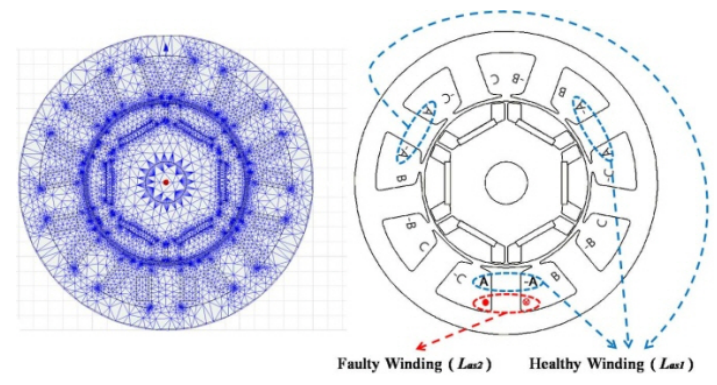

Fig. 6. FEM model with faulty winding.

waveforms, the inverter should be controlled to generate the $120^{\circ}$ current-conduction profile, which is synchronized with the flat portion of the back-emf profile, to generate a constant torque. Figure 8 shows the three-phase current without turn fault (a) and the three-phase current with fault (b) and (c). When a fault occurs, the number of shorted turns is either 3 $(\mathrm{Fr}=4.17 \%)$ or $6(\mathrm{Fr}=8.33 \%)$. The controlled $A$-phase current and the healthy-phase current that conduct to the faulty phase in the inverter increase with the fault fraction. This implies that more current will be required to maintain a given rotational speed and load as the fault worsens. Generally, many interturn fault studies verified the increasing current phenomenon at the faulty phase. Therefore, Fig. 9(a) is classified for faulty-phase current analysis. The faulty-phase current and the negative sequence component in the faulty current such as the fault fraction are analyzed as shown in Fig. 9(b). In the harmonic analysis, $2^{\text {nd }}$ harmonics are enlarged when the fault fraction increases. The negative sequence component in the faulty current is generated owing to a decrease in the backemf caused by the shorted turn. This implies that the threephase current asymmetry and subsequently the distorted torque induce greater vibration.

\section{B. Distributed Characteristics of Flux Density and Torque}

Here we propose a rate speed of $3500 \mathrm{rpm}$. In general, very high circulating current occurs when there is an inter-turn fault, and the phase is instantly destroyed because the heat generated increases in proportion to the square of current. Therefore, we performed the FEM simulation shown in Figs. 10 and 11provided fault fraction is increasing as time passes-to partly monitor the fault characteristics. As shown in Figs. 10 and 11 , the magnetic flux is distorted because of the input current waveform, which is affected by the circulating current, and directly influences the torque characteristic. Fig. 10 shows the flux density distribution with time. The proposed magnetic 


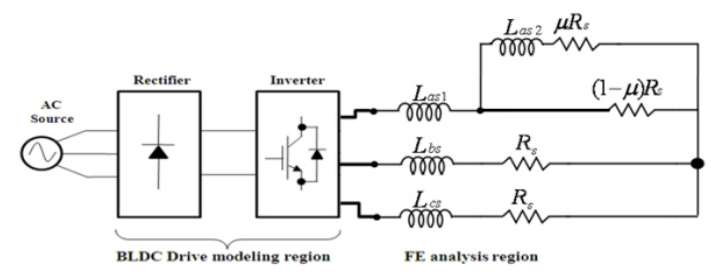

Fig. 7. Scheme of proposed FEM-based model with inter-turn fault.

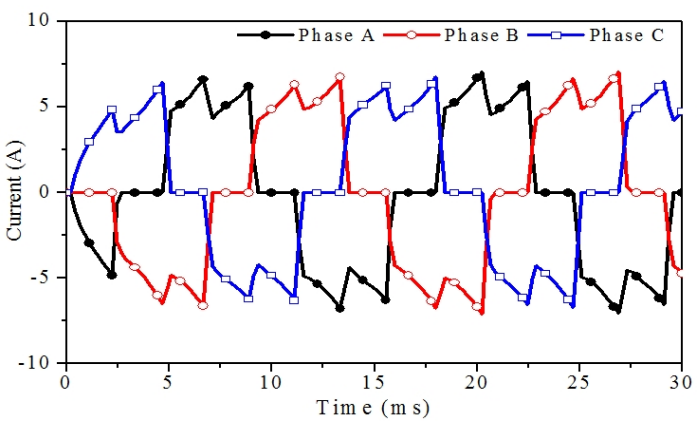

(a) Without fault $(F r=0 \%)$.

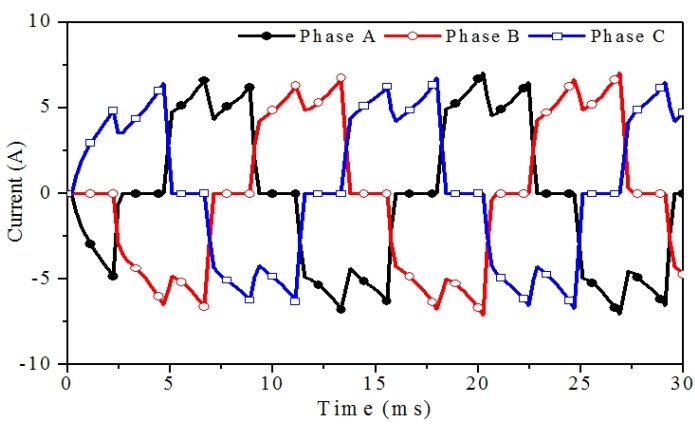

(b) With turn fault $(\mathrm{Fr}=4.17 \%)$.

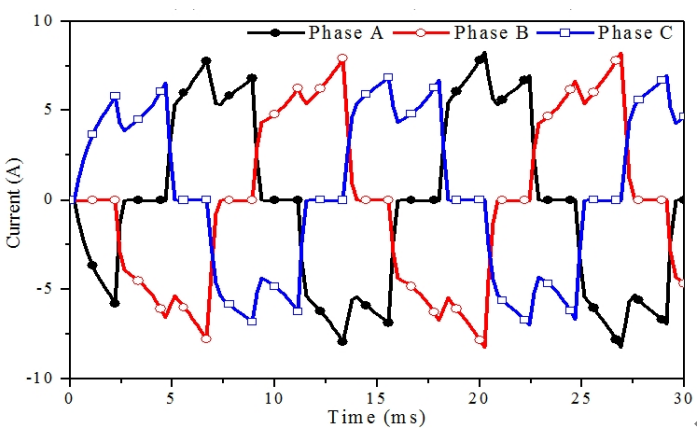

(c) With turn fault $(F r=8.33 \%)$.

Fig. 8. Input current variation.

field model generates circulating current in a direction opposite to that of the magnetic field, which is generated by the input current. Therefore, as the fault fraction increases with time, an opposing magnetic field is generated in the teeth with shorted turn and magnetic saturation occurs in the rest of the teeth.

When a small number of turns are shorted, the additional magnetic flux is not large. However, when a large number of turns are involved in an inter turn fault, the additional flux strongly distorts the distribution of the magnetic flux in the air gap. The flux density distribution is shown in Fig. 12 with and without fault. The commutation torque ripple with time is shown in Fig. 11. The average torque decreases and the torque ripple increases because of the opposing magnetic field caused

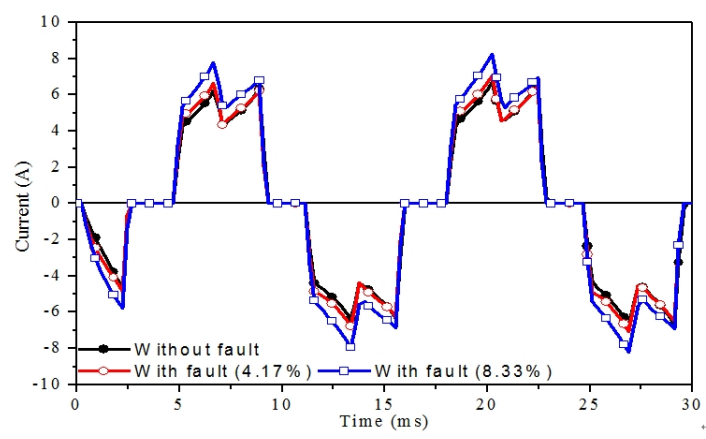

(a) Phase- $A$ current variation

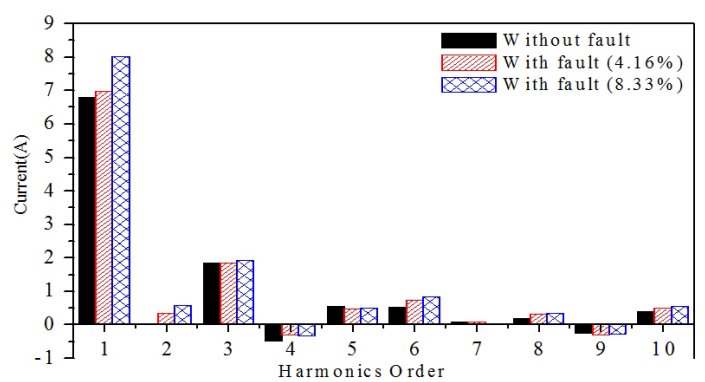

(b) Harmonics order of current.

Fig. 9. A-phase current analysis.

by the circulating current and the distortion of input current.

The torque ripple rate with time is shown in Fig. 13. The stator inductance in healthy state is $0.518[\mathrm{mH}]$, but it decreases to $0.387[\mathrm{mH}]$ when the fault fraction is $12.5 \%$. It is confirmed that the flux and self-inductance decrease due to shorted coil through the inductance profile in Fig. 14. The results of the harmonic analysis of the commutation torque are shown in Fig. 15. The analysis shows that the torque component increases $6 \mathrm{x}, 12 \mathrm{x}$, and $18 \mathrm{x}$ because of the interturn fault, where $x$ is the rotation frequency $(58 \mathrm{~Hz})$. This increase is attributed to the magnetic field generated due to the circulating current and is proportional to the pole number.

\section{Characteristics of Back-emf and Circulating Current}

The concentric winding of the machine and the rectangular distribution of the magnetic flux in the air gap cause the non-sinusoidal back-emf [15]. Fig. 16 shows the back-emf comparison of the proposed model's results and the test results from the inter-turn fault analysis at $1,500 \mathrm{rpm}$. Back-emf decreases as the fault fraction increases, because the fault fraction presents shorted turn emergence and, therefore, the healthy turn decreases. Fig. 17 shows the circulating current variation. The simulation results show that the circulating current increases as the fault fraction increases nonlinearly. Fig. 17 also shows the measured circulating current according to the change of the inter-turn fault condition with a motor speed of $1,500[\mathrm{rpm}]$. From the results, it is seen that the circulating current increases nonlinearly in proportion to the fault fraction, and the phase angle of the circulating current moves slightly toward the direction of rotation. This phenomenon can be explained by the inductance component of the time constant. Fig. 18 shows the comparison between the phase angle of the circulating current and that of phase $A$ current. 


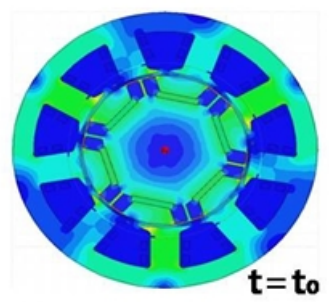

Without turn fault

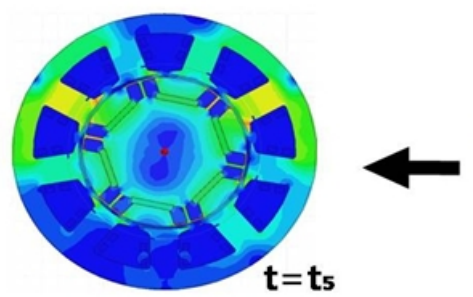

With turn fault (12.5\%)

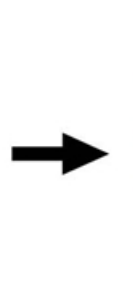

With turn fault (1.39\%)

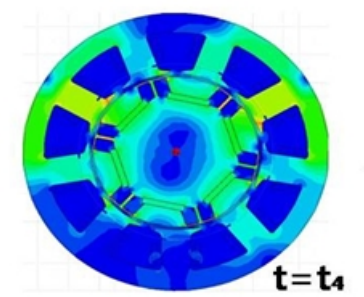

With turn fault $(8.33 \%)$

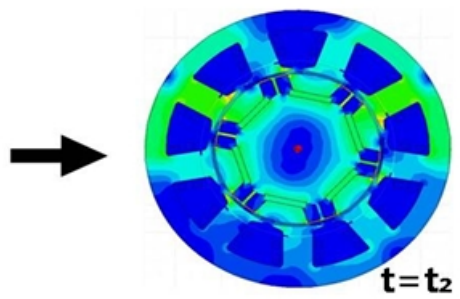

With turn fault (2.78\%)

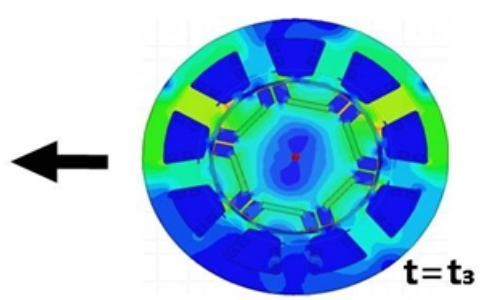

With turn fault (4.17\%)

Fig. 10. Flux density variation for $t_{5}$.
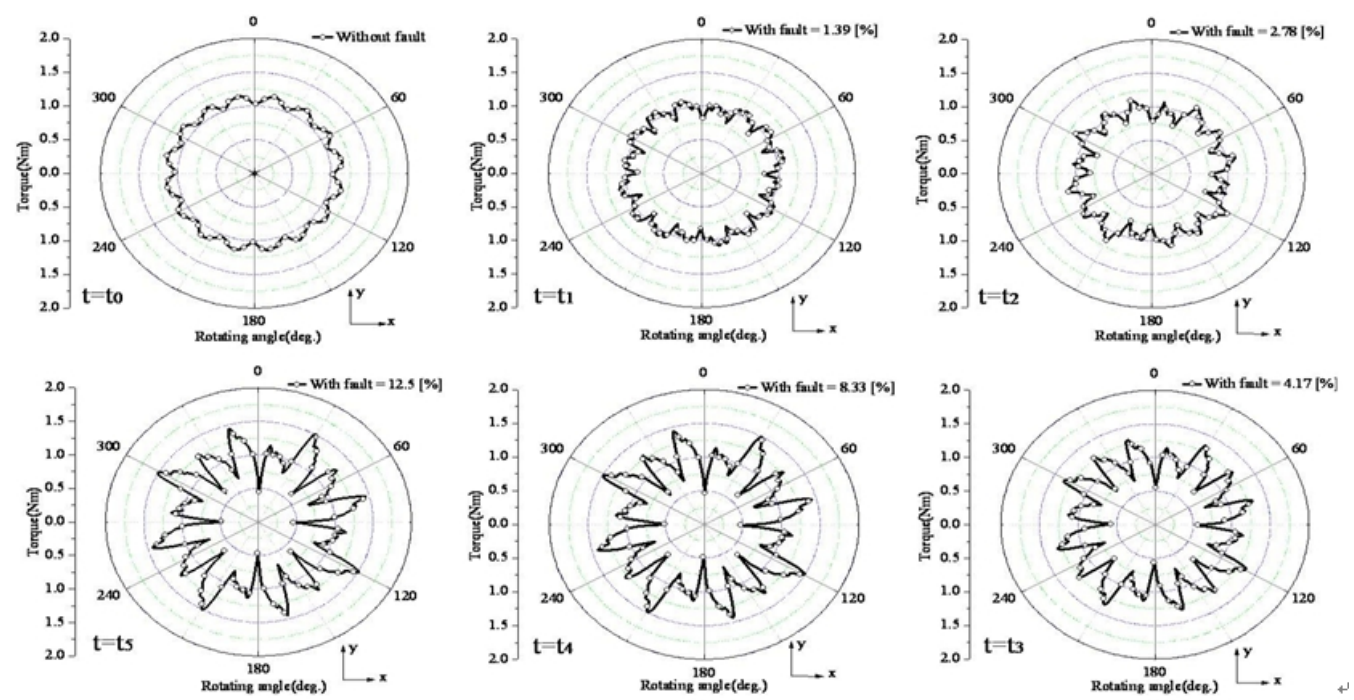

Fig. 11. Torque ripple variation for $t_{5}$.

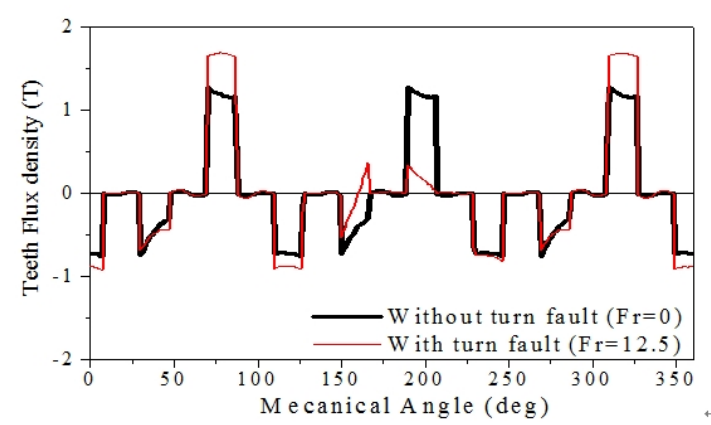

Fig. 12. Flux density distribution.

Based on the results, the inter-turn fault induces the difference phase angle and waveform as well as the amplitudes of the circulating current with the phase coil current. It is implies that the circulating current in the shorted turn has a negative rate of increase of magnetic flux, which is generated by the phase current and PMs, linking the turn. The difference between the

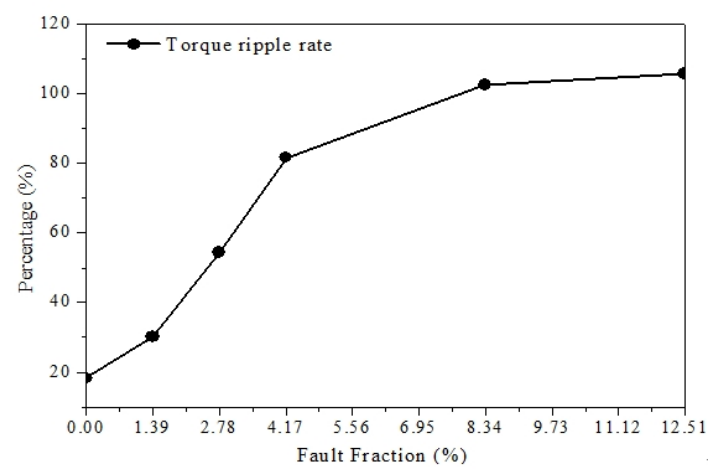

Fig. 13. Variation torque ripple rate.

values obtained in the simulation and those obtained in the experiment is caused largely because of the extended coil for measuring the circulating current. 


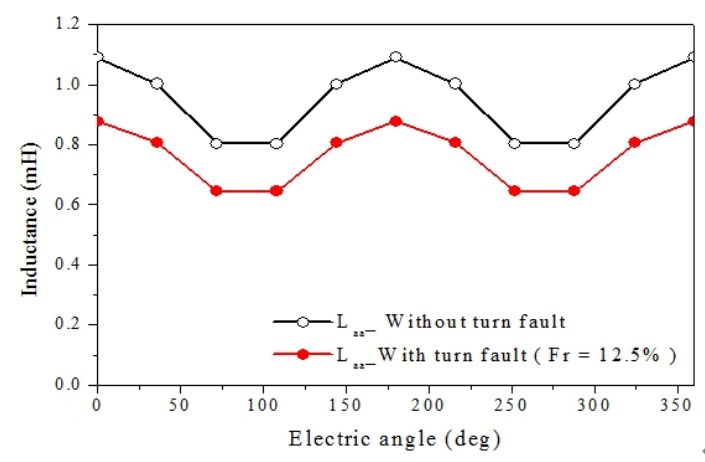

(a) Self-inductance of faulty phase.

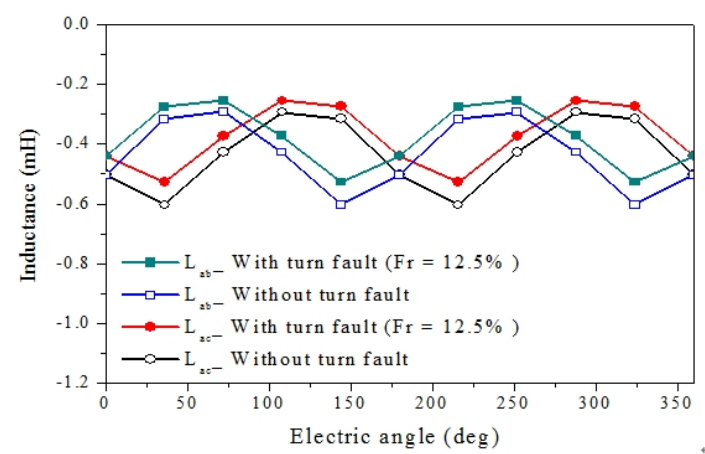

(b) Mutual-inductance of faulty phase.

Fig. 14. Inductance with fault $(\mathrm{Fr}=12.5 \%)$.

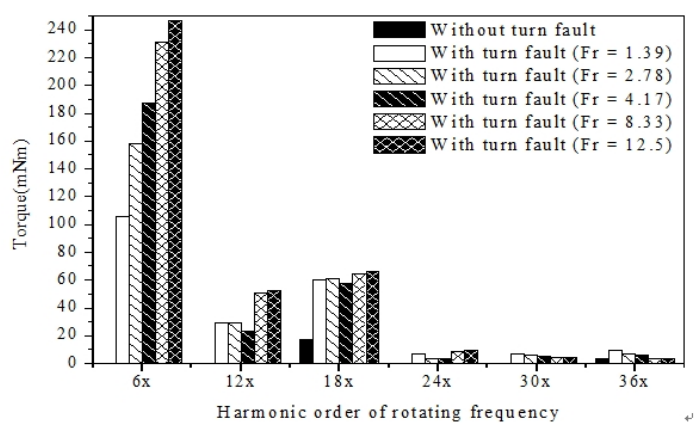

Fig. 15. Characteristics of harmonic components caused by turn fault.

\section{Fault Impedance}

The proposed fault impedance model was verified by comparing the FEM-based model and experimental values.

The impedance value obtained from Eq. (7) was compared with the FEM and the experimental results, as shown in Fig. 19. The experiment was performed to measure the fault phase voltage $\left(v_{a s 2}\right)$ and circulating current $\left(i_{f}\right)$. Subsequently, the fault impedance was calculated as $\left|Z_{f}\right|=v_{a s 2[\mathrm{rms}]} / i_{f[\mathrm{rms}]}$.

Fig. 20 shows the results of the measurement of $v_{a s 2}$ and if under the following conditions: fault fraction, 8.33[\%]; rotating speed, $2500[\mathrm{rpm}]$; voltage peak, $1.13\left[V_{r m s}\right]$; and circulating current peak, $52.9\left[A_{r m s}\right]$.

As shown in Fig. 19, the results obtained from the proposed simplified fault impedance model agree relatively well with the simulation and experiment results. The pure resistance model, however, resulted in large errors. However, we confirmed that this method can be applied to early detection, because the proposed model accurately estimates the circulating current in a small fault state, and it quite simply calculates the impedance

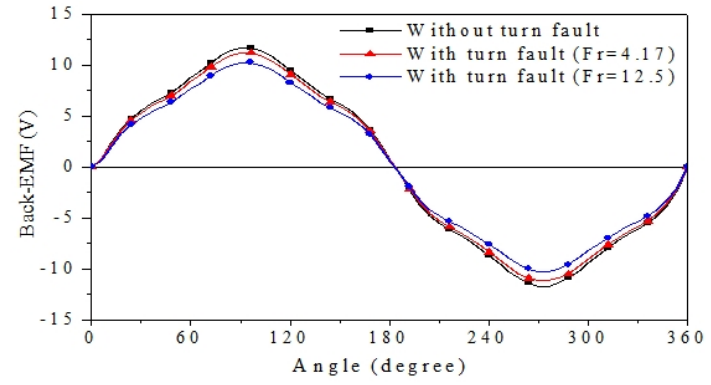

(a) Simulated back-emf.

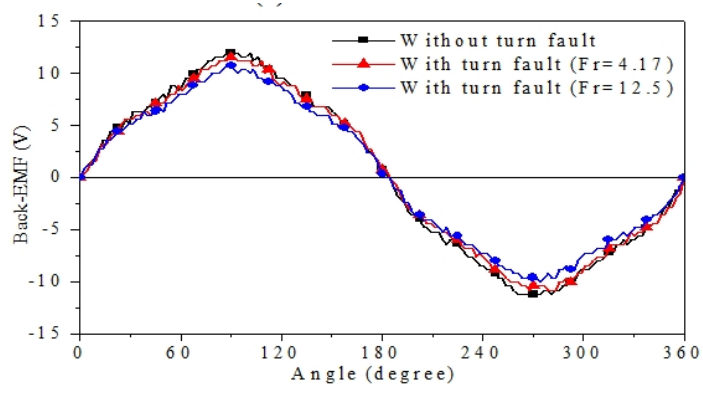

(b) Experimental back-emf.

Fig. 16. Back emf comparison of $A$-phase FE and test model.

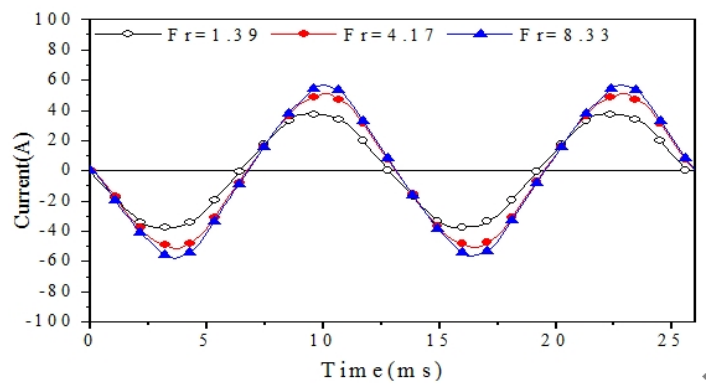

(a) Simulated circulating current.

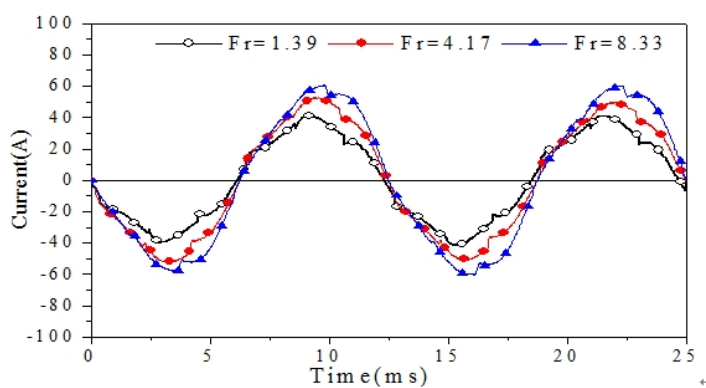

(b) Experimental circulating current.

Fig. 17. Circulating current at the fault.

of the fault state using the parameters of the healthy state and the fault fraction.

In particular, the inter-turn fault increased rapidly at the rated speed because the heat generated is proportional to the square of the circulating current. Therefore, the heat of the shorted turn is generally very high, as shown in Fig. 21. Because of its destructive nature, the early detection of a turn fault is imperative to prevent the complete loss of the motor or drive system. 


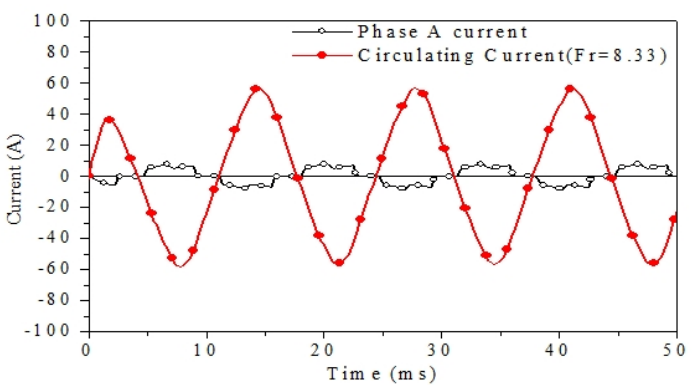

(a) Simulation.

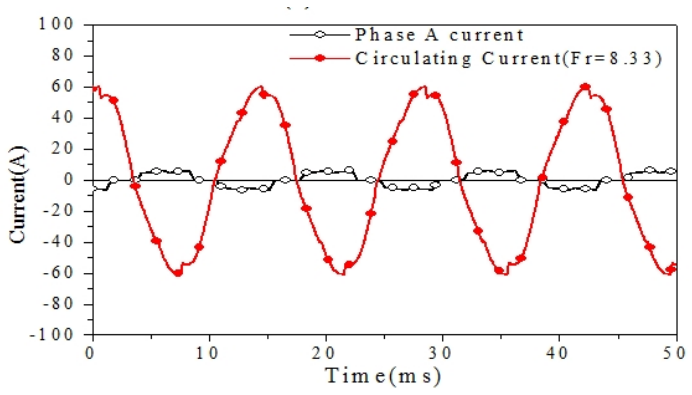

(b) Experiment.

Fig. 18. Comparison of phase angle at turn fault.

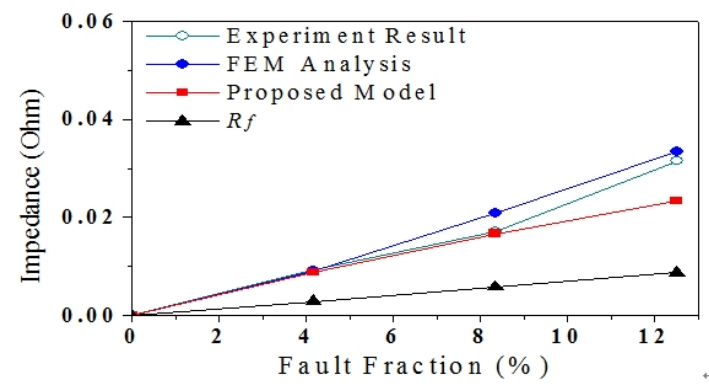

(a) Impedance (speed $=1500[\mathrm{rpm}]$ ).

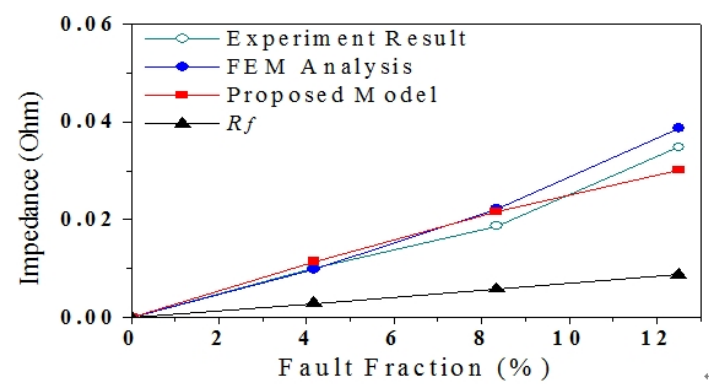

(b) Impedance $($ speed $=2000[\mathrm{rpm}]$ ).

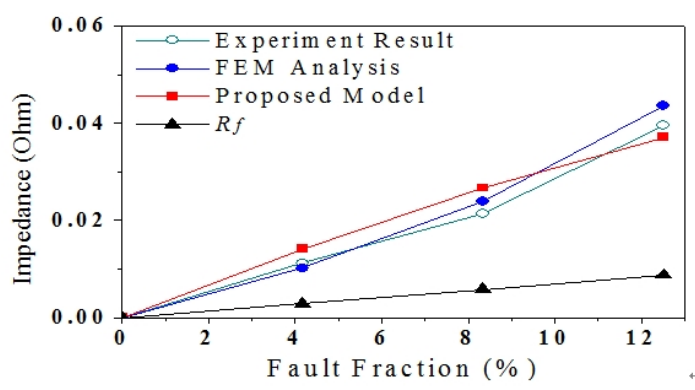

(c) Impedance $($ speed $=2500[\mathrm{rpm}]$ ).

Fig. 19. Comparison of impedance results.

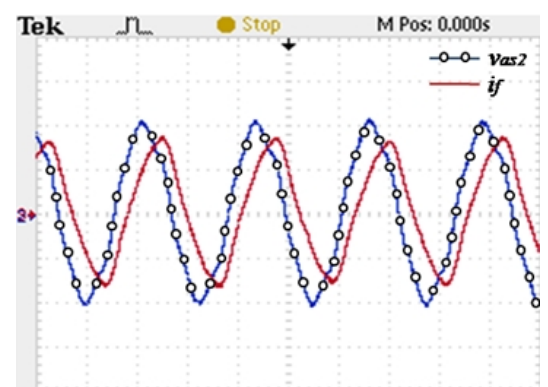

Fig. 20. Experimental result for $v_{a s 2}$ and circulating current.

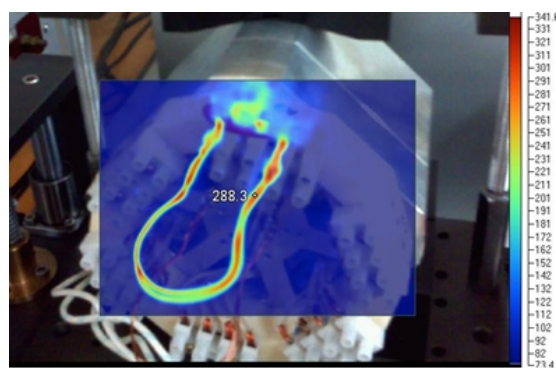

Fig. 21. Overheating of shorted winding $\left[{ }^{\circ} F\right]$.

\section{E. Characteristics of Input Phase Current at No-load and Load}

The phase current under no-load was measured to observe the change in the variation of the current in detail (Fig. 22).

Fig. 23 shows the phase current variation at load $(0.5[\mathrm{Nm}])$ and this experimental result can be confirmed by the data in Fig. 8. In Fig. 23(b) with turn fault ( $\mathrm{Fr}=8.33[\%])$, the faulty phase current has increased. In addition, the healthy phase current that conducted to the faulty phase in the inverter has increased. Therefore, the three-phase current is irregular and the torque ripple increases.

\section{F. Motor Performance}

Fig. 24 shows the test equipment for the experimental measurements, and Fig. 25 presents the motor performance test results. The motor speed is 4,250 [rpm] under no load. In the case of the fault model, the output power decreased because of the adverse affect of the circulating current.

From the results of the performance experiments, it is seen that the efficiency reduces by $50[\%]$ as the fault fraction progresses by $12.5[\%]$ compared to the no-fault case. In conclusion, the inter-turn fault seriously affects the efficiency.

\section{CONCLUSIONS}

This paper proposes a finite element method (FEM) model of an IPM-type BLDC motor having stator inter-turn faults. We also modeled the impedance of the magnetic characteristics. Thus, the developed model provides a powerful tool to investigate the characteristics of an IPM-type motor with inter-turn fault considering the variations in fault impedance. Moreover, the circulating current at the inter-turn fault is calculated using the proposed fault impedance $\left(Z_{f}\right)$. The circulating current can be calculated using the proposed fault impedance modeling.

Furthermore, the effectiveness of the proposed simplified fault impedance model was confirmed by comparing simulation and experiment results. The results showed that the 


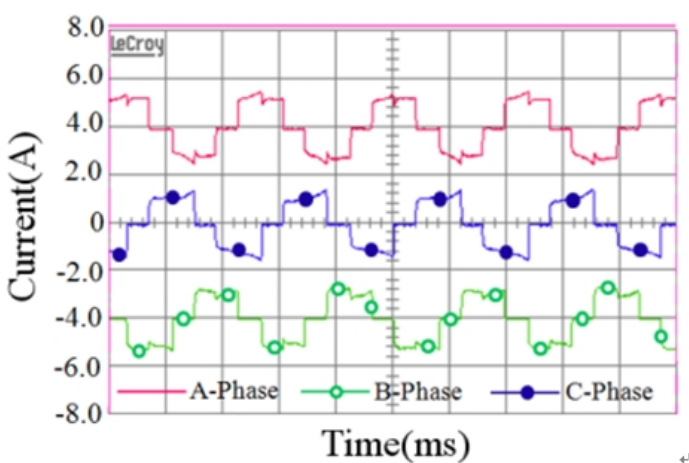

(a) With turn fault $(\mathrm{Fr}=1.39 \%)$.

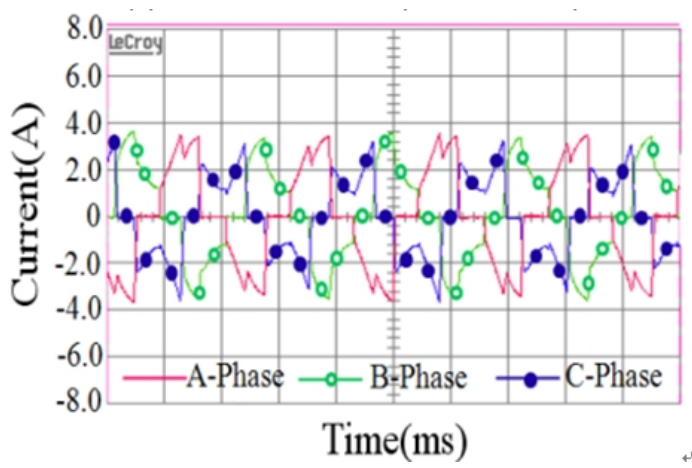

(b) With turn fault $(F r=8.33 \%)$.

Fig. 22. Experimental result for phase current variation under no-load condition.

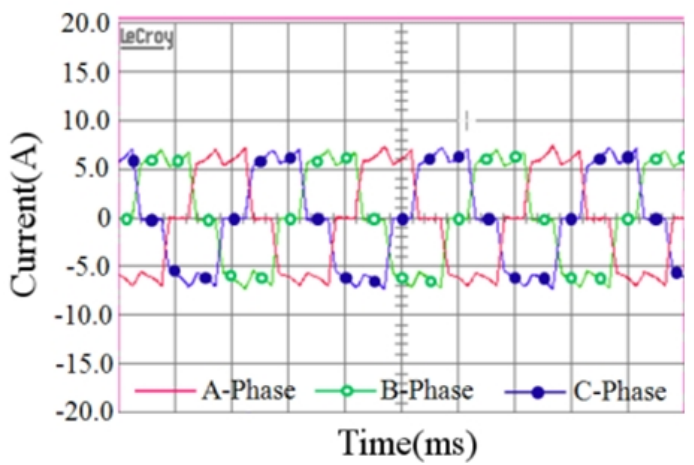

(a) With turn fault $(F r=1.39 \%)$.

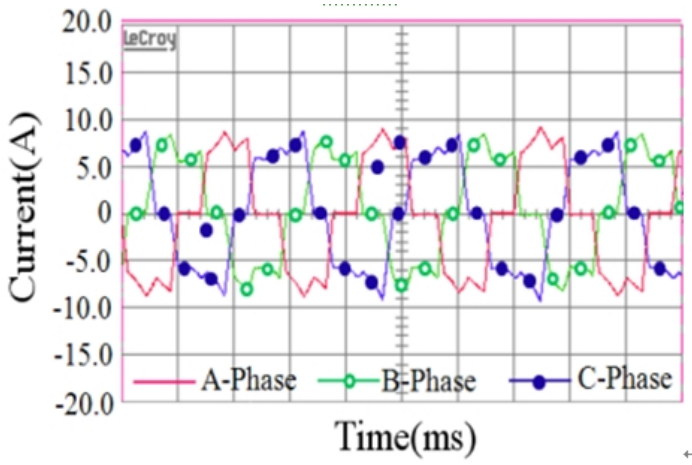

(b) With turn fault $(F r=8.33 \%)$.

Fig. 23. Experimental result for phase current variation under load condition.

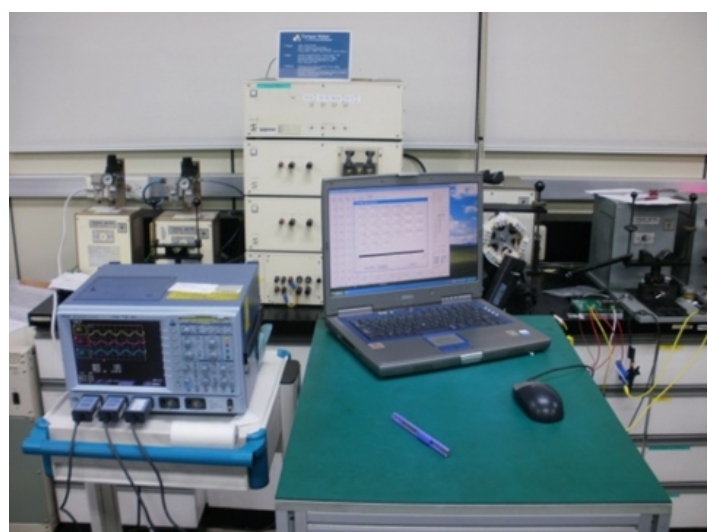

Fig. 24. Test equipment for the experimental measurements.

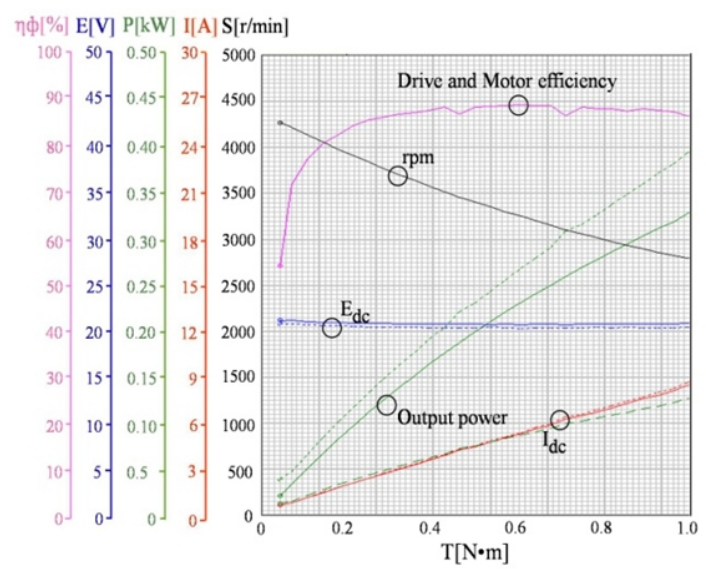

(a) Without turn fault.

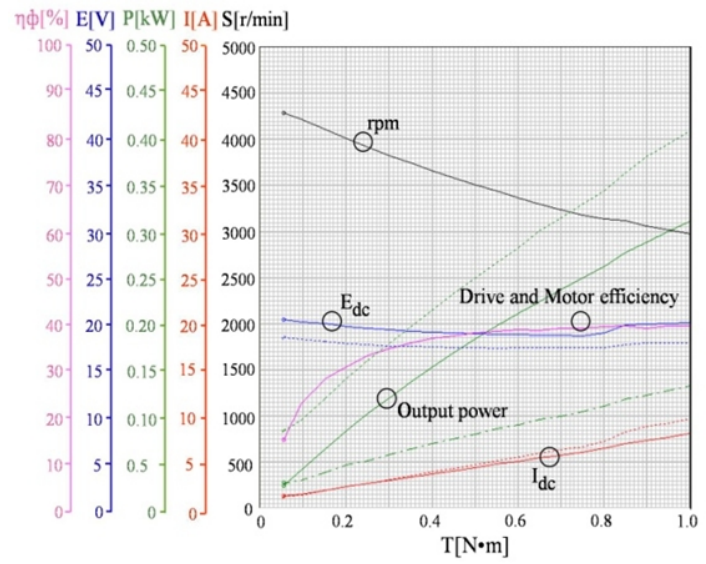

(b) With turn fault $(F r=12.5 \%)$.

Fig. 25. Designed test model for experimental measurement.

proposed model for detecting the turn fault of IPM motor at initial stage with small fault fraction can be used for a faultdiagnosis operating.

\section{REFERENCES}

[1] Jin Hur, "Characteristic analysis of interior permanent magnet synchronous motor in electro-hydraulic power steering system," IEEE Trans. Ind. Electron., Vol. 55, No. 6, pp. 2316-2322, Jun. 2008.

[2] H. Nakamura, T. Oono, and Y. Mizuno, "Analysis of current waveforms of induction motors with short circuit faults," Electrical Insulation and Dielectric Phenomena, CEIDP 2008. Annual Report Conference, pp. 56-59, 2008. 
[3] Y.-K. Lee, "A stator turn fault detection method and a fault tolerant operating strategy for interior pm synchronous motor drives in safetycritical applications," Ph.D. dissertation GIT, Aug. 2007.

[4] Q. Wu and S. Nandi, "Fast Single-turn Sensitive Stator Inter-turn Fault Detection of Induction Machines Based on Positive and Negative Sequence Third Harmonic Components of Line Currents," Industry Applications Society Annual Meeting, IAS '08. IEEE, pp. 1-8, 2008.

[5] T. Kim, H.-W. Lee, and S. Kwak, "The internal fault analysis of brushless dc motors based on the winding function theory," IEEE Trans. Magn., Vol. 45, No. 5, May 2009.

[6] B. Vaseghi, N. Takorabet, and F. Meibody-Tabar, "Fault analysis and parameter identification of permanent-magnet motors by the finiteelement method," IEEE Trans. Magn., Vol. 45, No. 9, pp. 3290-3295, Sep. 2009.

[7] Y. K. Lee and T. G. Habetler, "A stator turn fault tolerant strategy for induction motor drives in safety critical applications," Power Electronics Specialists Conference, PESC '06. 37 th IEEE, pp. 1-7, 2006.

[8] Y. K. Lee and T. G. Habetler, "A phase variable simulation model for interior PM synchronous motor drives with stator turn fault", Power Electronics and Motion Control Conference, EPE-PEMC '06. $12^{\text {th }}$ IEEE, pp. 1074-1079, 20006.

[9] O. A. Mohammed, S. Liu, and Z. Liu, "FE-based physical phase variable model of PM synchronous machines under stator winding short circuit faults," IET Sci. Meas. Technol., Vol. 1, No. 1, pp. 12-16, Jan. 2007.

[10] O. A. Mohammed, Z. Liu, S. Liu, and N. Y. Abed, "Internal short circuit fault diagnosis for pm machines using fe-based phase variable model and wavelets analysis," IEEE Trans. Magn., Vol. 43, No. 4, pp. 1729-1732, Apr. 2007.

[11] L. Romeral, J. C. Urresty, J. R. Riba Ruiz, and A. G. Espinosa, "Modeling of surface-mounted permanent magnet synchronous motors with stator winding interturn faults," IEEE Trans. Ind. Electron. Vol. 58, No. 5, pp. 1576-1585, May 2011.

[12] B. Vaseghi, B. Nahid-mobarekeh, N. Takorabet, F. Meibody-Tabar, "Experimentally validated dynamic fault model for pmsm with stator winding inter-turn fault," IAS Annual Meeting, pp. 1-5, Oct. 2008.

[13] K.-H. Kim, D.-U. Choi, B.-G. Gu, and I.-S. Jung, "Fault model and performance evaluation of an inverter-fed permanent magnet synchronous motor under winding shorted turn and inverter switch open," IET Electr. Power Appl., Vol. 4, No. 4, pp. 214-225, 2010.

[14] J. A. Farooq, A. Djerdir, and A. Miraoui, "Modelling and simulation of stator winding inter-turn faults in permanent magnet synchronous motors," COMPEL: The International Journal for Computation and Mathematics in Electrical and Electronic Engineering, Vol. 27, No. 4, pp. 887-896, 2008.

[15] T. J. E Miller, Design of Brushless Permanent Magnet Motor, Clarendo press, Oxford, 1994.

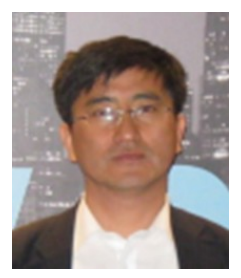

Byeong-Woo Kim received the B.S. and the M.S. degrees in mechanical engineering from Hanyang University, Seoul, Korea, in 1987 and 1990, respectively and the $\mathrm{Ph} . \mathrm{D}$. degree from in precision mechanical engineering from Hanyang University, Seoul, Korea, in 2002. From 1989 to 1990, he has been a Inviting Researcher at Precision Measurement Group, Japan Kosaka Research Institute (JKRI), Saitama, Japan. From 1990 to 1994, he has been a Junior Researcher at Sensor Development Group, CAS Cooperation, Seoul, Korea. From 1994 to 2006, he has been a Principal Researcher at Electrical \& Electronics Group, Korea Automotive Technology Institute (KATECH), Chunan, Korea. From 2006 Dr. Kim joins at School of Electrical, Electronics \& Information Systems Engineering, Ulsan University, Ulsan, Korea, as an Associate Professor. His research interests include electrical and electronics system for automotive applications, control systems for hybrid, fuel cell and electric vehicle systems. (E-mail: bywokim@ulsan.ac.kr)

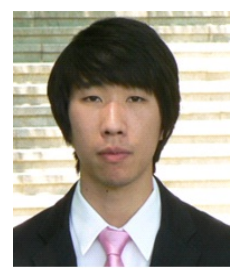

Kyung-Tae Kim was born in Busan, Korea, in 1984. He received the B.S. degrees in electrical engineering from the University of Ulsan, Ulsan, Korea, in 2010, Since 2010 , he is currently a master's course in University of Ulsan. His research interests are in the areas of motor design, motor diagnosis. (E-mail: kkt2782@nate.com)

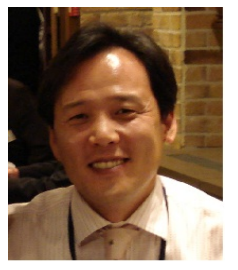

Jin Hur (S'93-M'98-SM'03) received Ph.D. degrees in electric engineering from Hanyang University, Seoul, Korea, in 1999. He was with Department of Electric Engineering, Texas A\&M University, College station, as a Postdoctoral Research Associate from 1999 to 2000. From 2000 until 2001, he was a Research professor of electrical engineering for BK21 projects, Hanyang University. From 2002 until 2007, he was a Director of Intelligent Mechatronics Research Center, Korea Electronics Technology Institute (KETI), Puchon, Korea, where he worked on development of special electric machine and systems. Since 2008, he has been an Assistant professor, School of Electric Eng., University of Ulsan, Ulsan, Korea. He is the author of over 140 publications in electric machine design, analysis and control, power electronics. He has 1 granted pending US patent and 20 granted pending Korea patent. His current research work is in high-performance electrical machines, modeling, drives, new concept actuator for special purpose and numerical analysis of electromagnetic fields. Dr. Hur is working as an Associate Editor for IEEE Transaction on Power and IEEE Transactions on Vehicular Technology. He is a general secretary and Publication chair of International Conference on Electric Machines and Systems (ICEMS) 2004, 2007, 2010. He is also IEEE Senior member and Technical Program Chair of IEEE VPPC2012 Conference. (E-mail: jinhur@ulsan.ac.kr) 